\title{
Study on the Way to the Development of Low Carbon Agriculture in Henan Province
}

\author{
Li peng $^{\mathrm{a}}$, Yahong LIANG $^{\mathrm{b}, *}$
}

Department of tourism and planning, Pingdingshan Universty, Pingdingshan, 467000, henan, China

aemail: pdsxylp@163.com, bemail:327937938@qq.com, ${ }^{*}$ corresponding author

Key words: Henan province, Low carbon agriculture, Way

\begin{abstract}
The development of low carbon agriculture is the development direction of future agriculture. Henan province is agricultural big province, significance of low carbon agriculture development is great, but there are some difficulties, such as agricultural waste of resources, low level of mechanization of agriculture, agricultural pollution is becoming more and more serious, agricultural product safety problems etc. Aiming at these problems, this paper puts forward some concrete measures for the development of low carbon agriculture in Henan province.
\end{abstract}

\section{Introduction}

Humans in the development of the economy is also undermining our living environment, in particular greenhouse gas emissions lead to global warming, has seriously affected the global climate, and has affected the survival of mankind. So the human reflection on their own development model, and made a positive action. In 2003, the British Government issued the "Energy White Paper", for the first time proposed the "low-carbon economy" concept [1], with this new economic development model to deal with climate change and environmental impact. "Low-carbon economy" and the current "oil economy" model is completely different, it is a low-power, low emissions and low pollution characterized by green economic development model[2-4]. "Low-carbon economy" not only can reduce greenhouse gas emissions, but also the economic development model, energy consumption, A major change in the way people live. It will transform all-round modern industrial civilization based on fossil energy and turn it into ecological civilization [5].

Agriculture is the primary industry, in our national economy occupies an important proportion. Low-carbon agriculture is an important part of low-carbon economy, low-carbon agriculture is the realization of low-carbon economy in the form of agricultural development. The United Nations Intergovernmental Panel on Climate Change Fourth Assessment Report (2007) pointed out that agriculture is the second largest source of greenhouse gases, agricultural sources of greenhouse gas emissions accounted for $13.5 \%$ of global anthropogenic emissions[6]. Henan province is a big agricultural province, the development of low-carbon agriculture is of great significance [7], only the development of low-carbon agriculture, it is possible to make the province's low-carbon economy development.

\section{Current Situation of Agriculture in Henan Province}

Henan Province, the current commonly used area of 720.22 hectares of arable land, the rural population of 49.11 million people, grain output 55.425 million tons, of which 31.23 million tons of wheat production. Henan Province as the main body of the Central Plains Economic Zone on the eve of the National Day 2011 rose to national strategy, in November 2012 the State Council approved the "Central Plains Economic Zone Planning", the Central Plains Economic Zone has a programmatic document. Central Plains Economic Zone, superior agricultural production conditions, is an important agricultural production in China. Grain production of more than 100 million tons, accounting for more than $18 \%$ of the country, of which 54 million tons of wheat 
production, close to $50 \%$ of the country, characteristics of agricultural and forestry products in the country occupies an important position. But there are also many contradictions and problems, such as serious waste of agricultural resources, low level of agricultural mechanization, agricultural pollution is becoming increasingly serious, agricultural product safety issues such as outstanding [8].

Waste of Agricultural Resources. Abuse of chemical fertilizers. China is the world's largest producer and consumer of fertilizer, accounting for $7 \%$ of the world's arable land consumption of the world's $1 / 3$ of fertilizer production. Henan Province, the amount of agricultural chemical fertilizers applied 6.7371 million tons, the average amount of $935.42 \mathrm{~kg}$ per hectare of arable land. In most areas, there is no scientific soil testing and fertilization, and the farmers are blindly pursuing high yield and abusing chemical fertilizers. As a result, the utilization rate of chemical fertilizers is only $30 \%-40 \%$, which is far lower than the $60-70 \%$ of the developed countries [9].

Pesticide utilization is low. China's annual use of pesticides is about 1.3 million tons, pesticide use in 2011 in Henan Province was 128,700 tons, in recent years the amount of pesticide showed a gradual upward trend. Due to excessive application and improper application methods, only 1/3 of the pesticide by crop absorption, the rest of the pesticide with rainwater into the soil, rivers, causing environmental pollution.

Waste of agricultural water. Henan Province in 2011 about 13.064 billion cubic meters of agricultural water, accounting for $57 \%$ of the province's water consumption. But irrigation water use coefficient is only 0.57 , that is, nearly half of the irrigation water from the water to the field due to leakage, evaporation and poor management and other reasons waste. Henan Province, the total number of water resources in the nation's 19th, per capita water resources are extremely dry area. Henan Province, the current water productivity is only $1.65 \mathrm{~kg} / \mathrm{m} 3$, water-saving space is still very large [10].

Low Level of Agricultural Mechanization. Henan Province, many people and less, the main farmers to take their own small-scale economic operation, so the main use of energy consumption is still a large medium and small machinery. The high technological content, low energy consumption, comprehensive ability, easy operation of large and medium-sized machinery and equipment scarcity, which resulted in the overall level of agricultural mechanization is not high, unreasonable ratio of equipment, making a lot can be replaced by small, backward, High energy consumption of agricultural machinery and equipment is still used.

Agricultural Pollution is Becoming More and More Serious. In recent years, Henan Province, serious pollution of agriculture, agricultural pollution has accounted for the amount of pollution in the province $1 / 3$ to $1 / 2$. Henan Province in 2011 chemical oxygen demand (COD) emissions of 1.4367 million tons, of which COD emissions The amount of 82.31 million tons; ammonia nitrogen emissions of 15.38 million tons, of which agricultural ammonia emissions of 66,200 tons. A large number of agricultural mulch film residues not only damage the soil structure, but also affect the agricultural environment. Agricultural production not only pollutes water, soil and atmosphere, but also poses a serious threat to the safety of agricultural products, human health and even the development of rural areas.

Agricultural Product Safety is Outstanding. Food safety is the focus of attention today, food poisoning incidents occur frequently, mostly because of excessive consumption of pesticide residues in food. Pesticide is indispensable in the production of agricultural production, Henan Province, $1 / 3$ of grain production is to rely on the use of pesticides to ensure. In recent years, the use of pesticides in Henan Province was on the rise, in 2011 the amount of pesticides used in agriculture was 128,700 tons, of which highly toxic pesticide use accounted for about $30 \%$. Excessive use of pesticides, the use of improper methods such as agricultural products is an important cause of insecurity.

\section{The Significance of Developing Low-Carbon Agriculture}

The Development of Low-Carbon Agriculture is an Objective Requirement for Sustainable Agricultural Development. Agriculture is the basic industry of the national economy. Only when 
agriculture achieves sustainable development can it realize the sustainable development of the whole society and economy. In recent years, the development of agriculture in Henan Province has made remarkable achievements, grain production to achieve nine even increased, but there are also non-renewable resources such as oil consumption, excessive use of pesticides, chemical fertilizers polluted rural soil, water, Air and agricultural products, resulting in environmental pollution and resource degradation of the dual consequences. The shortage of arable land, the shortage of water resources and the deterioration of ecological environment are the three major challenges to the development of agriculture in Henan Province, which seriously threaten the sustainable development of agriculture. Low-carbon agriculture is a modern agricultural development pattern characterized by low consumption, low pollution and low emission. The development of low-carbon agriculture is to alleviate the pressure of resources and environment brought by agricultural development and realize the sustainable development of agriculture. But also to explore not to sacrifice agriculture and food, ecology and environment at the expense of the new road of agricultural modernization and coordinated development, which is required by the Central Plains Economic Zone Planning.

The Development of Low-Carbon Agriculture is to Enhance the Competitiveness of International Agriculture, the Inevitable Choice. With the improvement of human living standard, more and more attention is paid to food safety. The international market demands for agricultural product quality, unit energy consumption index and environmental protection index are getting higher and higher. China's agricultural products used in the production of a large number of chemical fertilizers, pesticides, which led to a large number of pesticide residues in agricultural products, agricultural safety is not up to standard, but also makes the unit of energy consumption indicators of agricultural products higher than the importing country requirements, Thus reducing the competitiveness of China's agricultural products in the international market. Low-carbon agriculture advocates reducing the use of chemical fertilizers and pesticides, reducing energy consumption per unit of agricultural products and improving the quality of agricultural products to achieve carbon emissions and carbon footprint certification standards, thereby enhancing the competitiveness of agricultural products in the international market. Therefore, the development of low-carbon agriculture is to enhance the competitiveness of Henan Province, the inevitable choice of agriculture [11].

Low-Carbon Agriculture is the Way to Develop Modern Agriculture. The development of modern agriculture requires the modernization and high efficiency of agricultural machinery and equipment. The advanced agricultural machinery and equipment will be put into agricultural production and the level of agricultural mechanization will be greatly improved. Advanced agricultural machinery and equipment just in line with low-power, low pollution, low emissions, high efficiency, high output, high yield characteristics of low-carbon agricultural development model, so in rural areas to promote advanced agricultural machinery and equipment, out of small, Backward, high energy consumption of agricultural machinery and equipment. In order to promote the advanced agricultural machinery and equipment in rural areas, it is necessary to change the current peasant household individualized small-peasant model, speed up the rural land circulation, cultivate large farmer, develop farm business model.

\section{Specific Measures}

The Development of Fine Agriculture, Conservation of Resources. Play the role of agricultural service stations at all levels, the implementation of soil testing and fertilization, the use of the best fertilization methods to achieve scientific fertilization, on-demand fertilization, fine fertilization, to avoid waste of fertilizer. Promotion of straw to field technology, promote the construction of biogas digesters, promote nutrient material circulation. Combined with the farm, after the full treatment of the stool is a good organic fertilizer, can improve soil structure and increase soil fertility.

The promotion of advanced pesticide spraying equipment and technology to improve the utilization of pesticides, with the lowest amount to achieve the maximum effect.

Sprinkler irrigation, drip irrigation and other advanced irrigation technology to improve the 
utilization of agricultural water use, reduce unnecessary waste of water resources.

Enhance the Level of Agricultural Mechanization. Increase the support of farmers to buy advanced agricultural machinery to speed up the upgrading of backward agricultural machinery, research and development to promote scientific and technological content, energy consumption is low, comprehensive ability, easy to operate large and medium-sized machinery and equipment.

To Strengthen Rural Agricultural Environmental Regulation. Before the government's environmental protection department is generally concerned about the urban environmental conditions, rural agriculture, environmental pollution is not enough attention. Relevant departments should strengthen awareness of environmental protection in rural areas, strengthen rural environmental quality monitoring and management of agriculture, reduce pesticide, fertilizer, plastic sheeting use, strengthen the rural living garbage, wastewater treatment, improve rural energy structure, encourage the promotion of biogas digesters, solar energy Building, a better rural agricultural environment.

Attention to Agricultural Safety Issues. Research and development to promote varieties of pest-resistant crops, from the source to reduce pesticide use. R \& D promotion of biological pesticides, increase the safety of pesticide use. In the early stages of crop maturation, the prohibition of the application of pesticides difficult to break down. The implementation of scientific fertilization, on-demand fertilization, reduce waste of resources, with minimal consumption of resources to achieve maximum returns.

In today's increasingly deteriorating human environment, the development of low-carbon agriculture is gradually being human knowledge, acceptance and practice. Low-carbon agriculture is the only way for the development of modern agriculture, we should vigorously promote and promote resource-saving and environment-friendly low-carbon agriculture.

\section{Acknowledgement}

In this paper, the research was sponsored by the Humanities and Geography Key disciplines of Pingdingshan University.

\section{References}

[1]Department of Trade and Industry (DTI). UK Energy White Paper: Our Energy Future - Creating a Low Carbon Economy [R]. 2003.

[2] ZHANG Kun-min. China's Role, Challenges and Strategy for the Low Carbon World[J]. China Population, Resources and environment, 2008,18(3):0001-0007.

[3]LI Ming-xian. Technology Lock-in and Substitution Strategy of Low Carbon Agriculture in China [J]. Journal of Hunan Agricultural University (Social Sciences), 2010,11(2):1-11. [4]HE Shun-kui. Low-Carbon Agriculture: Inevitable Choiceof Agricultural Modernization [J]. Journal of Guiyang College(Natural Siences), 2010,5(3):39-41.

[5]WEI Bin, ZHANG Ling-Fei, GE Qing-ZHeng, et al. Advances on research of low-carbon agriculture[J]. Pratacural Science, 2012,29(4):528-533.

[6]IPCC. Climate Change 2007:Synthesis Report [R]. 2007.

[7]Sun Hong-xia. A Study on Existing Problems and Counter measures of Low-carbon Agriculture in Henan[J].Areal Research and development, 2011,30(5):97-102.

[8]SUI You-sheng. Low Carbon Agriculture and the Development of Zhongyuan Economic Zone [J]. Forward Position,2011,(7):118-121.

[9]MA Xiao-xu. The Dilemma of China 's Low Carbon Agriculture and the Way Out[J]. Reform of Economic System, 2011,(5):71-74. 
[10]LIU Chang-yin, HUANG xi-liang, LI Ju-xian. Study on Effect and Countermeasure of Developing High Efficiency Water-saving Irrigation in Henan Province [J]. China Water Resources,2012,(17):43-44.

[11]CHEN Tao. Discussion on Low-carbon Agriculture in the Construction of Central Plains Economic Zone - Taking Henan Province as an Example[J]. Journal of Anhui Agricultural Sciences, 2012, 40(18):9936-9938. 